\title{
Concentrated sugar belongs to the museum
}

\author{
F. M. Riegler
}

Published online: 18 April 2013

(C) Springer-Verlag Wien 2013

\section{Dear reader,}

Guess it is all about holiday, taking a break from surgery, going out into the heat of a wide bright summer day with your friends, families, and kids to forget about daily profession, troubles, duties, and forces. It is time for positive energies; dresses gets shorter, clothes colorful, and food gets manifold. So let us see what's up?

It is all about life style, nutrition, and undo disease (Fig. 1). Today we know, so we can do, theoretically. Mc. Western does not have to talk about political, racial, religious, and ethical enemies. Here we have to accept: Mc. Western life style diametrically distorts and out centers the metabolism of the homo sapiens. After more than 100,000 years, a significant portion of the homo sapiens is at risk to undergo self-inflicted metabolic extinction. This type of war exists since app. 12,000-15,000 years and is fought with an highly effective weapon: concentrated sugar, which immediately and rapidly true releases from the swallowed food after its trans-gullet transport logistics along the you tube thy chest into the sac of lack passing the stuff over to the all secreting sausage sous le coeliac trunk pan-propulsive digestive creative creator pump propeller from ampulla to ampulla, from junction to junction, from coin to mush to stool the fool. Space times time squares the energy from intriguing tight junction ion channel to cell to tell: Glory galaxy sky walker relaxes at both ends for the brilliant dancing stars of the endoderm: ribosome milky way is peanuts mitochondria for the universe. God results from an electrical discharge within the religious cortex. Micro to macrovilli: Archaic form of stroke where the cables double cross. Homo adapted to the world, somehow, designed, oriented the

\section{F. M. Riegler, MD ( $₫)$}

Manometry Lab \& Department of Surgery,

Medical University Vienna, Waehringer Guertel 18-20, 1090 Vienna, Austria

e-mail: franz.riegler@meduniwien.ac.at environment according to the needs and demands. Mirror the model to see how the deviated kinky fat super size dripping wheezer Mc. Burger stands at the end of the evolution, exclusively. Time to change the model? Self made, Mc. mad made Darwinism. Economy is food + war industry, leaving a fruitful gap for trauma surgery, oncology, and metabolic medicine. The rest calls for abstracts sent to the waste paper basket. A given species is suggested to exist for 4 million years.

We know that the unique sensible organism of the human flute does not tolerate unlimited intake of concentrated sugar. The faster the food the slower the mood. Once upon a crime over time from generation to generation repeated effective exposure to high concentrated sugar formats the genetic program toward metabolic dysbalance. Likewise gravity formats the destiny of the train on the rail (Fig. 2). Accurately hobbling Dr. House challenges emergency room at the cost of Gray's Anatomy, reputation counts, market prize winner world. The weakest falls first to weaken the chain. Thus, genetics trigger the type and location of the manifestation of the metabolic dysbalance, which of course exposes to the cells continuously, always and highly effective, as can be seen from the syndromes and diseases listed in the text books of medicine (there is no diabetes-, obesity-, hypertension-, coronary heart disease-, and cancer-free edition!). The enormously powerful, reliable, and highly effective metabolic hammer strikes the sorry salvage thunder, poisons, stresses and unmasks the tragedy in the form of numerous somehow well and not well-defined life style and food related disorders: the ones listed above and the so-called damn autoimmune self biter diseases (chronicles of Crohn, you see ulcerative colitis, Hashimoto, asthma, sclero the derma, lupo runs red rush hour) and last but not the least the peak potent pharao of all maladies: respect cancer.

Molecules mill mixture moisture of means out of tune for the stream of mood, here the well-known postpran- 
Fig. 1 Spectrum of delicious foods containing large amounts of concentrated sugars, which foster metabolic dysbalance, as described in the text
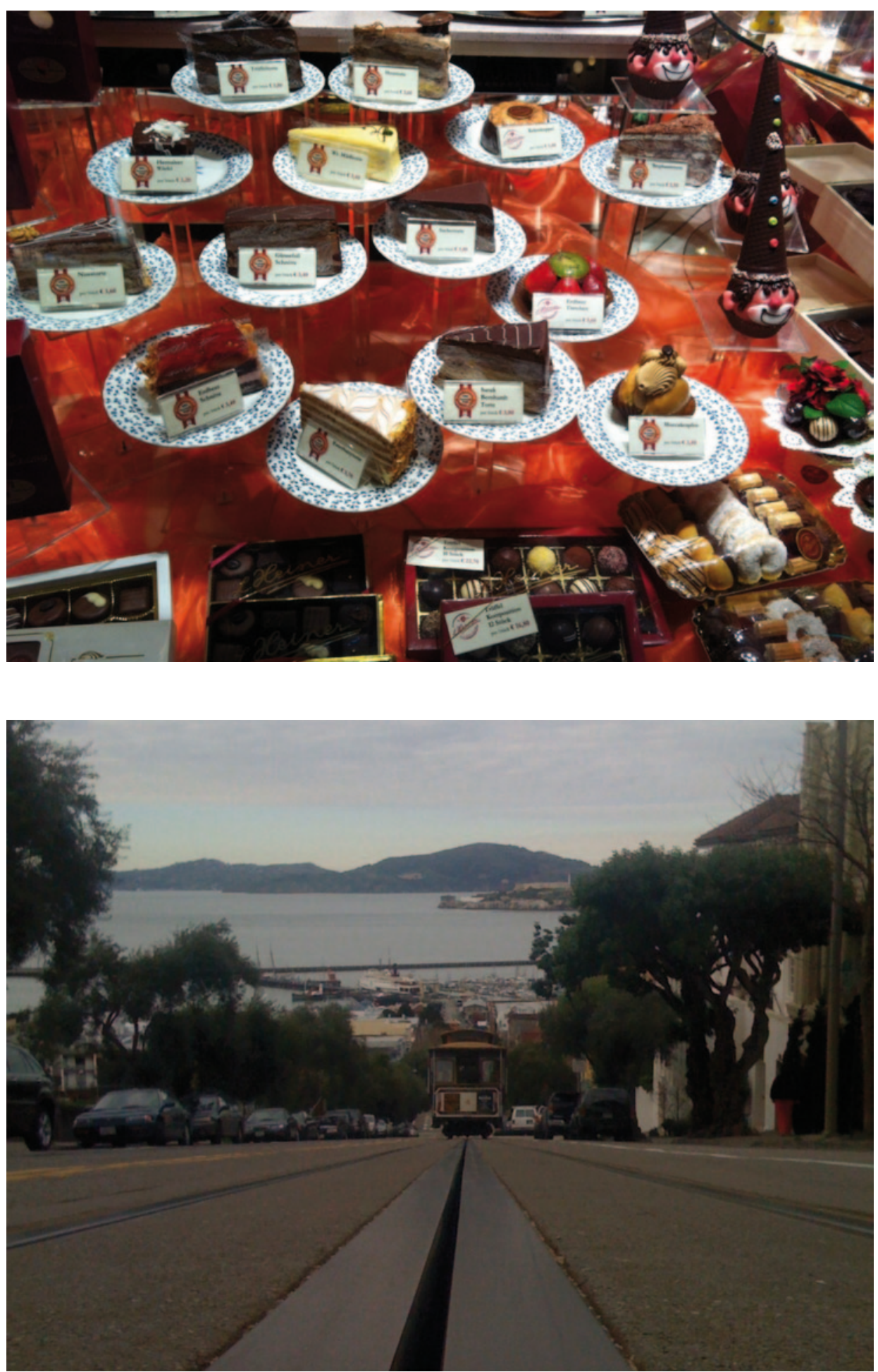

Fig. 2 Following the forces of gravity events move along the rail. (Image obtained in San Francisco using iPhone technology) dial hypoglycemic dilemma repeatedly occurs: close your eyes. Actor ages the receptor activated transmembrane domain stimulated catastrophic cascade of enormous elaborating nihilistic phosphate group mediated events. Pure presence matters, not the concentration, sugar shuffles you sick. Nutrition needs harmonic melody makers to outbalance and restore the life quality and the productivity. Sub specie aeternitatis the nutrition acts direct, fast, and highly effective. For example, initially so-called natural civilizations (Papua New Guinea; Australia; South and North Pacific; Africa; South America; Arctic belt) did not know diabetes and obesity, hypertension and coronary heart disease. However, accurately following the Mc. Western life style (too sweet, too often, too much, and no physical activity) for two to three generations, diabetes ( \pm obesity, hypertension, etc.) affects $20-50 \%$ of these populations today. Mc. Western civilizations (EU, USA, Japan, etc.) produce communication technology 
mediated, food industry driven metabolically distorted and disarranged individuals who harbor a significant risk to become autistic, miserable, unhappy resting lipomatic asteroids unable to move and migrate, having landed to develop conditions, which in fact significantly impair their life quality and productivity. China, India are on the way to effectively share the same destiny and become successful copy-pasters of the Mc. Western life style including the copy-paste metabolic diseases. Filet open without sugar in the menu may be worth and valuable for print out, but not yet, because USA and Europe do not need a political enemy, they are eradicating themselves with concentrated bull bubbled sugar mines, alcohol bombs, nicotine explosives and will get stuck as well defined $6 \mathrm{ft}$ at last contours within the terminal twilight of the googled earth at the dawn of a particular very long day. The Mc. Western civilizations will not need to go to war, lipomas do the job, will get stuck in the entrance to the bombing machines and vehicles. War market shrinks. Like a tablet computer war game the principle of Shiwa repeats and the next day will belong to the metabolically outbalanced generation: traditional civilization based Africans, Asians, South Americans will come and take over after having removed the lipomas and their poison producing factories: see them cease and hang in the hangar. Food industry shrinks. Then the wheel of civilization will undergo a new invention, hopefully without making the mistakes of our current times. As the num- bers decline, diseases shrink. Well being remains. Why is it all going so fast and highly effective? It is all because of the nerves, and nerves cry, ejaculate wonderful waves of beautiful neuropeptides, electrolytes, lights, microns, and electrons. Fuse space and time, throw it away at the speed of light and you will get energy over mass (Übermass). Enlightenment teaches the bright: Concentrated sugar is sensed by nerves provoking a transmission of information toward the effector tissues at nerve conductance speed $(1-50 \mathrm{~m} / \mathrm{s})$. These high-speed cables trigger a complex neurohumoral chain reaction aggravating the metabolic dysbalance by affecting the Joslin nutritional wall street stock exchange factory at the liver, pancreas, kidney and causing symptoms and pathologies (inflammation, tumor development, etc.). Manifestation of the metabolic dysbalance depends on the genetic format because of the family history. Along the brain gut axis the manifestations range from depression to diarrhea. Being out of balance means being out of battery. Conceptually outbalanced sugar intake should aid to eliminate the noxious side effects the Mc. Western diet. At skin ex silva bar for saliva secretions. Concentrated sugar belongs to the museum: watch it, but do not touch and eat it. Take care, recharge your battery, enjoy summer, stay tuned.

\section{Conflict of interest}

The author declares that there exists no conflict of interest. 